Brit. J. industr. Med., 1960, 17, 41.

\title{
A COMPARISON OF THE EMOTIONAL STABILITY OF COAL-MINERS AND RAILWAYMEN
}

\author{
BY \\ JUDITH S. LION \\ From the Nuffield Department of Industrial Health (University of Durham), \\ King's College, Newcastle upon Tyne
}

(RECEIVED FOR PUBLICATION FEBRUARY 2, 1959)

\begin{abstract}
A comparison has been made of the emotional stability of coal-miners with that of railwaymen. Sixty-seven miners and 50 railwaymen were given a small battery of objective tests of emotional instability. A clinical group of 17 psychiatric patients diagnosed as emotionally unstable was also tested.

Tests of significance were carried out comparing the scores of the miners with those of the railwaymen and the railwaymen with the clinical group. In addition a factor analysis was made of the scores of the miners.

A comparison of the miners and railwaymen on Heron's test of emotional instability revealed a significant difference, the miners scoring more emotionally unstable scores than the railwaymen. The remaining tests, with the exception of those for fluency and hand persistence, failed to discriminate between these two groups.

Heron's test (both parts) was also the only one to reveal significant differences between the clinical group and the railwaymen. These were in the expected direction.

The results on Heron's test suggest that miners are less stable than railway workers and this is attributed to the environmental stresses of mining. It is suggested that many tests purporting to measure emotional instability are too sensitive to other personality variables.
\end{abstract}

This paper describes a study made to determine whether coal-miners are more emotionally unstable than workers in another industry. It formed part of a larger investigation into the emotional stability of miners, in which the present author was able to show (Lion, 1958) that miners suffering from nystagmus were more unstable than miners without the disease. It has been suggested (Heron and Braithwaite, 1953) that coal-miners who work underground are not as stable as those employed above ground. In this research, a group of miners and a group of railway workers were compared on a small battery of objective tests of emotional instability to see whether there was any significant difference between them.

\section{Method}

The Miners.-Sixty-seven men were selected at random. Their mean age was 55 years and they were all coalface workers, having spent an average of 30 years at the coalface. This group will be referred to as "the miners". Further details of their selection are given in the paper on the initial study of nystagmus (Lion, 1958).

The Railwaymen.-These men, selected from the same area, were employed in a variety of jobs ranging from engine drivers to porters. Their mean age was 52 years and none of them had ever worked in the mines. They were attending routine biennial medical examinations and the first 50 men to attend, in the appropriate age group, were selected.

\section{The Tests}

Heron 1 (1956): A Two-Part Personality Inventory.This two-part personality measure consists of 110 statements which can be answered as "true" or "not true" self descriptions by the subjects. The first part, 74 items, contains $\mathbf{2 0}$ items which are used as the basis for a score of emotional maladjustment. Most of the remaining items are buffers which cause the section as a whole to appear as a "health inventory".

In the original validation, the test was given to more than 1,600 people and "has been used widely under various conditions in industry and elsewhere" (Heron, 1956). This test had a misclassification rate of only $13 \%$ when given to Heron's original sample of "normals" and neurotic patients in hospital.

Heron 2. - The second part of the measure consists of 36 items, 12 of which are used as the basis for a score of sociability (Heron, 1956).

Annoyances (Bennett, 1945).-This test records the 
number of items which the subject records as annoying him from a list of 60 possible annoyances.

Food Aversions (Wallen, 1945).- This is the number of aversions recorded from a list of 24 items of food.

Hand Persistence (Eysenck, 1947). - The number of seconds the subject can maintain his grip on a hand dynamometer at two-thirds of his maximum grip.

Fluency '(Eysenck, 1947).- - The number of "round" objects a subject can name in one minute.

Leg Persistence (Eysenck, 1947).- The number of seconds the subject can hold his right leg fully extended at a given distance above a chair.

All of these tests except Heron 2 have been shown to discriminate between "normals" and "neurotics'. Heron 2 is a test of sociability but not of emotional instability.

\section{Results}

Comparison of Groups.-The histogram (Fig. 1) demonstrates the difference between the two groups on Heron 1 showing the higher percentage of railway workers at the low scores and the greater percentage of miners at the high scores. Heron considers scores of 0 to 7 as "probably well adjusted", scores of 8 and 9 as "doubtful", and scores over 10 as "probably maladjusted".

Table 1 shows the mean scores for both groups on the seven tests with the appropriate levels of significance for differences between the groups.

On Heron 1, the main test of emotional instability, Student's $t$ test showed the difference between the two groups to be significant $(P<0.01)$. On the hand persistence test the miners scored significantly higher $(\mathrm{P}<0.01)$ than the railway workers, i.e., they showed greater persistence. The fluency test discriminated between the two groups at the 0.02 level of significance, the miners obtaining lower (more neurotic) scores than the railwaymen.

The results on Heron 1 (see Table 1) suggest that

TABLE 1

MEAN SCORES AND LEVELS OF SIGNIFICANCE

\begin{tabular}{|c|c|c|c|c|}
\hline \multirow[b]{2}{*}{ Tests } & \multicolumn{2}{|c|}{ Mean Scores } & \multirow[b]{2}{*}{$\mathbf{t}$} & \multirow[b]{2}{*}{$\mathbf{P}$} \\
\hline & $\begin{array}{c}\text { Railway } \\
\text { Workers } \\
(\mathrm{N}=50)\end{array}$ & $\begin{array}{c}\text { Miners } \\
(\mathbf{N}=67)\end{array}$ & & \\
\hline $\begin{array}{l}\text { Heron } 1 \text { (emotional } \\
\text { instability) } \\
\text { Heron } 2 \text { (unsociability) } \\
\text { Annoyances } \\
\text { Food aversions } \\
\text { Hand persistence } \\
\text { Fluency } \\
\text { Leg persistence }\end{array}$ & $\begin{array}{r}6 \cdot 00 \\
5 \cdot 32 \\
38 \cdot 68 \\
3.98 \\
43 \cdot 88 \\
8 \cdot 64 \\
54 \cdot 16\end{array}$ & $\begin{array}{r}8 \cdot 12 \\
5.91 \\
37.08 \\
4.51 \\
57.49 \\
7.18 \\
60.36\end{array}$ & $\begin{array}{l}3.20 \\
1.22 \\
0.65 \\
0.87 \\
2.76 \\
2.48 \\
0.66\end{array}$ & $\begin{array}{c}0.01 \\
\text { ns } \\
\text { ns } \\
\text { ns } \\
0.01 \\
0.02 \\
\text { ns }\end{array}$ \\
\hline
\end{tabular}

ns $=$ not significant.

Fig. 1.-The difference between the two groups shown by the Heron 1 test.

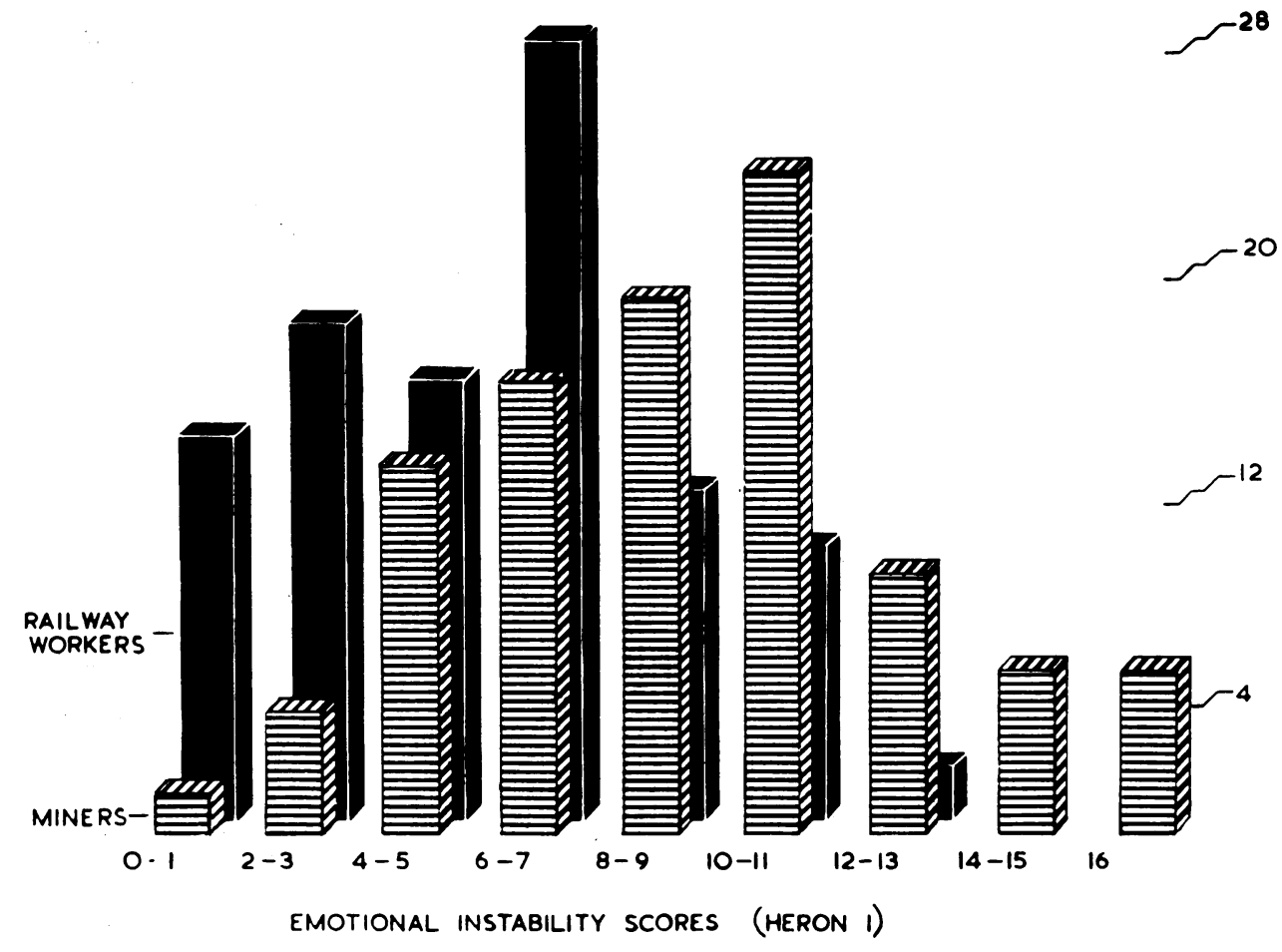


miners are more unstable than railway workers. However, the author felt that this test overemphasized undue preoccupation with health. Six of the 20 items scored in the test seemed to be concerned solely with this, and it was felt that the significant difference obtained between the two groups might be due to the miners being more preoccupied with their health rather than to any difference in emotional stability. This is of the utmost importance as miners, because of the very nature of their work, might justifiably worry more about their health than others who work in a less dangerous occupation. These six items were:-

No. 5 I am troubled by sick headaches.

23 My eyesight is sometimes blurred.

33 My bowels are not opened every day.

44 My physique is excellent.

55 I have no particular physical or health problems.

69 I catch cold frequently.

In order to overcome this possible bias the score of each man in both groups was re-calculated omitting these six items. In fact, this recalculation produced a greater difference between the two groups, $t$ being $4.09(P<0.001)$. A possible explanation of this may be that owing to the rigorous nature of their life miners are less concerned with trivial complaints.

An attempt was later made to validate the battery by testing 17 out-patients of a psychiatric clinic, all diagnosed by a psychiatrist as being neurotic. The small number in the group was due to the great difficulty in obtaining subjects, but it was considered large enough to compare their scores with those of the railwaymen.

Student's $\mathrm{t}$ test revealed significant differences between the two groups on Heron $1(P<0.001)$ and on Heron $2(\mathrm{P}<0.05)$. These differences were in the expected direction; the annoyances test discriminated in the opposite direction from that expected, i.e., the railwaymen obtained significantly higher scores $(P<0.02)$ than the neurotic group. The remaining tests revealed no significant differences between the two groups.

Factor Analysis.-The scores of the 67 miners were intercorrelated (Table 2) and the matrix factor analysed using the centroid method with three iterations. After the third iteration the obtained communalities did not differ from those used as estimates in the last iteration by more than \pm 0.02 .

Three factors were extracted, accounting for $32.6 \%$ of the variance. Two rotations were carried out. The criteria employed in rotating were: (1) to maximize the number of zero or near zero loadings; (2) to seek a positive manifold.

The rotations were as follows:-

$$
\mathrm{f}_{2} \text { with } \mathrm{f}_{3} \text { at } 35^{\circ} \text { giving } \mathrm{F}_{2}^{\prime} \text { and } \mathrm{F}_{3}{ }^{\prime}
$$$$
f_{1} \text { with } f_{3} \text { at } 45^{\circ} \text { giving } F_{1}^{\prime} \text { and } F_{3}^{\prime \prime}
$$

Table 3 shows the factor loadings and communalities of each test on the three factors before and after rotation and the direction in which the tests were scored.

Fig. 2 shows the final position of the tests on factors 1 and 3. The most probable interpretation

TABLE 2

INTERCORRELATION MATRIX

\begin{tabular}{|c|c|c|c|c|c|c|c|}
\hline Test & $\begin{array}{c}\text { Scoring } \\
\text { Direction }\end{array}$ & 1 & 2 & 3 & 4 & 5 & 6 \\
\hline $\begin{array}{l}\text { Heron } 1 \text { (emotional instability) } \\
\text { Heron } 2 \text { (unsociability) } \\
\text { Annoyances } \\
\text { Food aversions } \\
\text { Hand persistence } \\
\text { Fluency } \\
\text { Leg persistence }\end{array}$ & $\begin{array}{l}\text { Many } \\
\text { Many } \\
\text { Many } \\
\text { Many } \\
\text { Low } \\
\text { Few } \\
\text { Low }\end{array}$ & $\begin{array}{l}0 \cdot 107 \\
0 \cdot 088 \\
0 \cdot 158 \\
0 \cdot 153 \\
0.097 \\
0 \cdot 267\end{array}$ & $\begin{array}{r}-0.104 \\
0.256 \\
0 \cdot 160 \\
0 \cdot 190 \\
0 \cdot 190\end{array}$ & $\begin{array}{r}-0.127 \\
-0.007 \\
0.008 \\
0.101\end{array}$ & $\begin{array}{r}-0.193 \\
0.127 \\
-0.064\end{array}$ & $\begin{array}{l}0.022 \\
0.412\end{array}$ & 0.063 \\
\hline
\end{tabular}

TABLE 3

FACTOR LOADINGS AND COMMUNALITIES OF EACH TEST BEFORE AND AFTER ROTATION

\begin{tabular}{|c|c|c|c|c|c|c|c|c|c|c|}
\hline \multirow{2}{*}{ No. } & \multirow{2}{*}{ Tests } & \multirow{2}{*}{$\begin{array}{c}\text { Scoring } \\
\text { Direction }\end{array}$} & \multicolumn{4}{|c|}{ Unrotated } & \multicolumn{4}{|c|}{ Rotated } \\
\hline & & & $f_{1}$ & $f_{2}$ & $f_{3}$ & $h^{2}$ & $F_{1}$ & $F_{2}$ & $F_{s}$ & $h^{2}$ \\
\hline $\begin{array}{l}1 \\
2 \\
3 \\
4 \\
5 \\
6 \\
7\end{array}$ & $\begin{array}{l}\text { Heron } 1 \text { (emotional } \\
\text { instability) } \\
\text { Heron } 2 \text { (unsociability) } \\
\text { Annoyances } \\
\text { Food aversions } \\
\text { Hand persistence } \\
\text { Fluency } \\
\text { Leg persistence }\end{array}$ & $\begin{array}{l}\text { Many } \\
\text { Many } \\
\text { Many } \\
\text { Many } \\
\text { Low } \\
\text { Few } \\
\text { Low }\end{array}$ & $\begin{array}{r}0.40 \\
0.58 \\
-0.06 \\
0.33 \\
0.42 \\
0.23 \\
0.48\end{array}$ & $\begin{array}{r}-0.18 \\
0.27 \\
-0.24 \\
0.49 \\
-0.46 \\
0.13 \\
-0.45\end{array}$ & $\begin{array}{r}0.33 \\
-0.19 \\
0.21 \\
0.27 \\
-0.32 \\
0.08 \\
-0.04\end{array}$ & $\begin{array}{l}0.30 \\
0.44 \\
0 \cdot 11 \\
0 \cdot 42 \\
0 \cdot 50 \\
0 \cdot 08 \\
0 \cdot 43\end{array}$ & $\begin{array}{l}0.55 \\
0 \cdot 19 \\
0 \cdot 18 \\
0 \cdot 19 \\
0.30 \\
0 \cdot 16 \\
0.50\end{array}$ & $\begin{array}{r}0.04 \\
0.12 \\
-0.08 \\
0.56 \\
-0.57 \\
0.15 \\
-0.39\end{array}$ & $\begin{array}{r}-0.02 \\
-0.63 \\
0.26 \\
-0.27 \\
-0.30 \\
-0.17 \\
-0.18\end{array}$ & $\begin{array}{l}0.30 \\
0.44 \\
0.11 \\
0.42 \\
0.50 \\
0.08 \\
0.43\end{array}$ \\
\hline
\end{tabular}




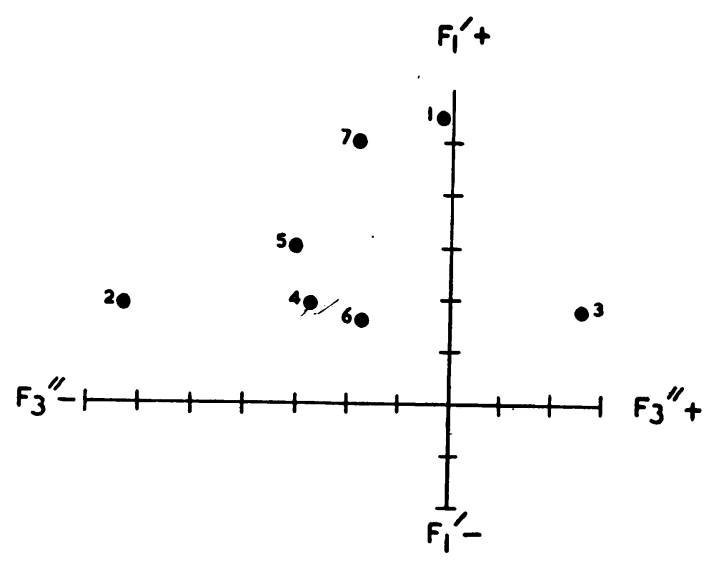

FIG. 2.-Relation between $F_{1}$ and $F_{2}$ after final rotation.

of these factors appears to be as follows:-

$F_{1}=$ Emotional instability

$F_{2}=$ Possibly a factor of persistence

$F_{3}=$ Unsociability

\section{Discussion}

The first suggestion that miners are less stable than others came from Halliday (1943) who held that miners applying for sickness benefit were more neurotic than other workers who applied. Heron and Braithwaite (1953) have since provided evidence that miners working at the coal-face are more neurotic than those employed above ground.

There is certainly much evidence to suggest that miners work in an environment which may be especially conducive to the development of neurosis. Despite the enormous improvements in safety during recent years there are still many accidents, and even in 1956 the total number of men killed in pit accidents in Great Britain was as great as $\mathbf{3 3 0}$ (Ministry of Power Statistical Digest, 1956). A large number of the miners in the present series had been involved in some minor accident, and it was not uncommon for a man to have one or two fingers missing. Living in such a close-knit community, these accidents are a constant reminder of the hazards of his occupation. Fear of developing pneumoconiosis, the incidence of which is very high in this area, may be an additional worry. In four pits in County Durham $50 \%$ of the miners over the age of 56 who had chest radiographs taken showed evidence of pneumoconiosis (McCallum, Browne, and Campbell, 1955). The miner is conscious at all times that any of these occupational hazards would entail a great reduction in his earning capacity.

It is probably his daily working conditions which provide the greatest stress of all. Continually work- ing in semi-darkness, lacking fresh air, he is constantly inhaling coal dust. The seams are often so low that he cannot stand up, and he is always cramped, perhaps crawling on his stomach or working lying on his side for up to eight hours at a time.

Ross, Miller, Leet, and Princi (1954) have described a study of 40 miners who were hospital patients for respiratory complaints. They concluded, after a thorough psychiatric examination of each case, that only $12.5 \%$ of the patients had a disability on purely physical grounds alone, and that psychoneurosis was the most significant diagnosis in onethird of their patients. They attributed this mainly to the environmental stresses of mining.

However, none of this is evidence that miners are any more neurotic than workers in other industries, and it was to determine whether this is so that this study was made.

The factor analysis has thrown some light on the reason for only three of the tests discriminating between the two groups (see Table 1). Heron 1 and leg persistence are the only tests of emotional instability to have a high loading solely on $F_{1}$. With all the other tests of emotional instability having small loadings on $F_{1}$, it seems justifiable to regard it as a factor of emotional instability.

It can be seen that hand persistence has an equally high loading on $F_{3}$, a factor orthogonal to $F_{1}$. Heron's test of unsociability also has a very high loading on $F_{3}$, and it could therefore be identified as a factor of unsociability.

The fairly high loading of the two persistence tests on $F_{2}$ suggests that this factor might be one of persistence, but it is difficult to reconcile this with the high negative loading of food aversions on this factor. The significant difference obtained between the means on the hand persistence test (the miners having greater persistence), could be interpreted as implying that they are less neurotic than the railway workers. However, it seems more likely that the significant difference obtained has a purely physical explanation in that miners are constantly using hand tools. This may also account for the scores on the leg persistence test on which the miners showed greater persistence than the railwaymen though this difference was not significant.

The results on the remaining test in the battery are not very conclusive. Fluency is the only other test to discriminate in the appropriate direction and it has not a high enough loading on $F_{2}$ to be regarded as a strong measure of emotional instability.

The factor analysis does to a certain extent support the results on the validation of the 17 psychiatric patients. Admittedly this number is small but it is remarkable that Heron's inventory was the only test to discriminate between this group and the 
railwaymen. These results, together with the factor analysis, confirm Heron's (1955) view that most tests of emotional instability are also sensitive to differences on other personality dimensions. This makes it inadvisable to use them as pure measures of emotional instability.

This study has shown the difficulty of applying personality tests to different groups of people; in some instances these groups are differentiated by characteristics which themselves may selectively prejudice their responses. For example, one cannot administer a body sway test to men suffering from nystagmus since postural disturbance is itself a symptom of the disease. However, if tests which are really sound measures of a particular dimension of personality are to be used in research and clinical diagnosis, it is vital that they are insensitive to these external variables and have a basis in the more fundamental characteristics of the dimension they are supposed to be measuring.

These results justify the writer in concluding, from the results on Heron 1, that the main hypothesis concerning the stability of underground workers has been supported.

The author wishes to thank all the miners and railwaymen who took part so willingly; Dr. J. P. Child and Dr. J. J. Justice, of St. Thomas' Clinic, Newcastle upon Tyne, for providing the psychiatric group; Dr. Gray of the North-East Branch of British Railways for making it possible to test the railwaymen; Professor R. C. Browne, Dr. Alastair Heron, and Dr. N. Loveless for their criticism and advice; Mr. D. J. Newell for statistical assistance; and Mrs. D. Weightman for help with the tables and graphs.

\section{REFERENCES}

Bennett, E. (1945). Brit. J. med. Psychol., 20, 271.

Eysenck, H. J. (1947). Dimensions of Personality. Kegan Paul, London.

Halliday, J. L. (1943). Psychosomat. Med., 5, 71

Heron, A., and Braithwaite, D. (1953). Brit. J. industr. Med., 10, 27.

- (1955). Educ. Psychol. Measmt, 15, 117.

- (1956). Brit. J. Psychol., 47, 243.

Lion, J. S. (1958). Brit. J. industr. Med., 15, 204

McCallum, R. I., Browne, R. C., and Campbell, H. (1955). Ibid., $12,279$.

Ministry of Power (1956). Statistical Digest. H.M.S.O., London.

Ross, W. D., Miller, L. H., Leet, H. H., and Princi, F. (1954). J. Amer. med. Ass., 156, 484

Wallen, R. (1945). J. abnorm. soc. Psychol., 40, 77. 